\title{
Docência e modos de subjetivação: dissoluções genealógicas e o cuidado de si
}

\author{
Betina Schuler \\ Universidade do Vale do Rio dos Sinos | São Leopoldo
}

\section{Resumo}

Este artigo problematiza a docência e seus modos de existência no presente. Para tanto, opera-se com as três dissoluções genealógicas apontadas por Foucault la verdade, a realidade e a identidade) na esteira dos estudos de Nietzsche. Tal procedimento busca pensar outras possibilidades de exercício consigo mesmo em se tratando da docência. Esta investigação conceitual procura desmanchar minimamente os universais que circulam como explicadores da docência para dissolvê-la na problematização dos modos de subjetivação, no que se refere à relação com os saberes e com a discência além de uma lógica de autorrevelação.

Palavras-chave: Docências. Dissoluções genealógicas. Modos de subjetivação.

\section{Teaching and modes of subjectivation: genealogical dissolutions and the care of the self}

\section{Abstract}

This article problematizes teaching and its modes of existence in the present. It operates with the three genealogical dissolutions pointed out by Foucault (truth, reality, identity) following Nietzsche's studies. This procedure seeks to think other possibilities of the relationship with the self in teaching. This conceptual investigation tries to dislocate the universal values that work as an explanation of teaching to problematize modes of subjectivation in teaching in its relation with knowledge and students beyond a self-revelation logic.

Keywords: Teaching. Genealogical dissolutions. Modes of subjectivation. 


\section{Docencia y modos de subjetivación: disoluciones genealógicas y el cuidado de sí}

\section{Resumen}

Este artículo problematiza la enseñanza y sus modos de existencia en el presente. Para eso, trabajase con las tres disoluciones genealógicas señaladas por Foucault (la verdad, la realidad y la identidad) siguiendo los estudios de Nietzsche. Ese procedimiento busca pensar en otras posibilidades de ejercicio consigo mismo en lo que dice respeto a la enseñanza. Esa investigación conceptual busca deshacer mínimamente los universales que circulan como explicadores de la enseñanza, para la disolver en la problematización de los modos de subjetivación, tratándose de la relación con los saberes y con el aprendizaje, avanzando más allá de una lógica de autorrevelación. Palabras-clave: Enseñanzas. Disoluciones genealógicas.Modos de subjetivación.

\section{Alguns lugares da docência: breve entrada}

Entrar em si mesmo e não encontrar ninguém durante horas,é preciso conseguir isso. Ser solitário como se era quando criança, quando os adultos passavam para lá e para cá, envolvidos com coisas que pareciam importantes e grandiosas, porque esses adultos davam a impressão de estarem tão ocupados e porque a criança não entendia nada de seus afazeres.

Um dia, ao percebermos que suas ocupações são mesquinhas, que suas profissões são enrijecidas e não estão mais ligadas à vida, por que não olhar para eles como uma criança que observa algo de estranho, a partir da profundeza do próprio mundo, da amplitude da própria solidão, que é ela mesma um trabalho, um cargo e uma profissão? Por que se desejaria trocar o sábio não entendimento de uma criança pela atitude defensiva e pelo desprezo, uma vez que o não entendimento é estar sozinho, mas a atitude defensiva e o desprezo são participações naquilo de que, com esses recursos, as pessoas querem se afastar? (RILKE, 2011 , p. 56).

A docência vem sendo transformada em tema de pesquisa na área da Educação a partir de diferentes perspectivas. As teorias denominadas de tecnicistas discutiam-na como uma questão neutra, tendo a função de instrução e 
transmissão de conhecimentos, compactuando com a ideia de que o processo formal de educação se trata de uma máquina de ensinar conteúdos (SILVA, 1999; MATOS; 2009). Nesse sentido, a docência estaria conectada aos princípios de eficiência, controle, adaptação social e padronização, sendo considerada o centro do processo de ensino e de aprendizagem.

Essa docência lida com a realidade como tendo um sentido em si mesma, a qual se pode ter acesso com base em bons métodos. A partir daí, essa verdade poderia ser transcrita pela linguagem e ser repassada aos alunos. Assim, a relação da verdade com tal docência é uma questão de sua descoberta e de uma realidade essencial, garantida por uma identidade unificada e centrada. Nesse sentido, a relação com os saberes se dá a partir de um entendimento de que, com a descoberta da verdade impressa nessa realidade dada, tais elementos possam ser espelhados pelos conhecimentos, os quais devem ser transmitidos e memorizados pelos alunos.

Já as teorias denominadas de críticas trazem toda uma denúncia do que Freire (1987, 1999), por exemplo, chamou de uma educação bancária. Essas discussões entendem que as práticas educacionais vêm sendo apropriadas como espaço de reprodução das desigualdades sociais e econômicas. Todavia, a partir de uma ação de tomada de consciência sobre os processos de dominação e de transformação da realidade, a educação poderia ser vista como possibilidade de libertação da ideologia opressora. Desse modo, há um importante deslocamento, pois a docência é invadida por uma dimensão política que abre para a reflexão sobre o mundo e para a possibilidade de transformação do mesmo mediante os processos educativos.

Nessa perspectiva, os conceitos de conscientização, cidadania e participação impregnam a existência em se tratando da docência. Com esses deslocamentos, a verdade é operada como algo que está mascarado e a realidade é entendida pelo conceito de diversidade. Tal postura remete fortemente a uma outra relação com os saberes, uma vez que quebra com suas hierarquias, na valorização dos chamados saberes populares. Nessas teorias, a docência parece assumir esse lugar de mediação entre os sujeitos e o mundo, e entre os sujeitos e os saberes. Assim, ela é invadida por uma perspectiva pastoral, na busca da conscientização e salvação dos demais.

Já as teorizações, denominadas de pós-críticas, pós-estruturalistas e o denominado pensamento da diferença, rompem com os binarismos e com as 
metanarrativas educacionais para pensar a educação como política cultural, envolvida fortemente na produção de regimes de verdade, efeitos de poder e modos de subjetivação. Nesse sentido, essas teorizações pensam a verdade como um valor que esqueceu que o é e como efeito das relações de forças na esteira de um pensamento nietzschiano e foucaultiano.

Operam com a realidade a partir da virada linguística que entende, segundo Foucault (2002a), que as palavras não são as coisas e nem representam as coisas, mas produzem as coisas das quais falam. Entendem que o que temos por realidade não existe fora dos processos discursivos, fora da linguagem que a produz como tal. Operam, ainda, com o desmanche da identidade, entendendo que a docência não é uma essência, uma substância, uma forma idêntica a si mesma, mas modos de existência, lugares no discurso, efeitos de subjetivação.

Nessa perspectiva, a relação com os saberes se daria na medida em que são entendidos como sendo produzidos a partir de determinadas condições de possibilidade, como imposição de sentidos (FOUCAULT, 2005). Nesse sentido, a docência entra em relação com os saberes e o currículo escolar como práticas discursivas e não-discursivas que produzem o que temos por realidade, pelo mundo e por nós mesmos. A relação entre docência e discência é problematizada quanto à função pastoral de salvação, deslocando-a para a análise dos regimes de verdade no presente e para a criação de outras possibilidades de pensamento e de existência.

Assim, pode-se acompanhar,nas últimas décadas, uma rigorosa produção sobre a docência com base nessas perspectivas que rompem com a lógica metafísica. Popkewitz (2001) discute a função pastoral que os professores vêm assumindo, envolvidos em complexos processos de normalização social. Diaz (1 999) aponta que não há docência fora do discurso pedagógico que o produz como tal. Ó (2009) traz o professor envolvido com a arte de governo e aponta $\circ$ atravessamento da docência nas práticas de governamentalidade que conectam as práticas do eu com as práticas de governo. Pignatelli (2000) opera com a discussão sobre o quanto os professores são produzidos pelos regimes de verdade do nosso tempo, e das possibilidades de problematização de tais regimes com uma postura docente que discuta a corrente prescritiva.

Veiga-Neto e Saraiva (2011) trazem a educação e a formação de professores no deslocamento do jogo do pastor para o jogo da cidade 
na perspectiva do conceito de governamentalidade, aliando processos de individualização e o governo das populações. Pereira (2010) discute a formação de professores a partir da necessidade de pensá-la como espaço de problematização, além da tradição que entende que a realidade tem um sentido em si mesma, marcando a necessidade de analisarmos as racionalidades por meio das quais produzimos nossas práticas e modos de existência. Concomitantemente, o autor traz a experimentação de outras possibilidades em educação a partir da necessidade de rigor, apontando o perigo de se cair em modismos, estereótipos, banalizações, prescrições ou de se renunciar a si mesmo a fim de alcançar algum padrão.

Loponte (2013) aborda a docência pensada a partir da possibilidade de invenção de si mesmo e não pela descoberta de um eu que estaria oculto ou de uma consciência a ser resgatada. Garcia (2009, 2002, 2002a) analisa a constituição da docência na problematização dos discursos críticos. A partir daí, a autora aponta que esse lugar da docência não se trata de uma norma ou de um dado natural, mas de práticas discursivas e não-discursivas que atravessam as experiências de si e que produzem os docentes a se reconhecerem de alguns modos e não de outros. Sommer (2007) e Coutinho e Sommer (2011) discutem a produção de modos de existência no âmbito da docência com base em uma análise do discurso escolar, que obedece a determinada ordem que sanciona e/ou interdita certa circulação das práticas discursivas escolares e que essa docência está vinculada a uma específica arte do governo das condutas. Corazza (2011) discute a docência vista como indissociável da pesquisa como aquele que adota um ponto de vista criador, isto é, aquele que está envolvido mais do que na resolução de problemas já postos, na invenção dos próprios e novos problemas.

Muitos outros autores poderiam aqui ser citados, mas o objetivo não foi a exaustão, porém mostrar que existem diferentes composições teóricas, diferentes arranjamentos conceituais para falar da docência a partir dessas perspectivas que dissolvem o sujeito. As produções anteriormente referidas, apesar de algumas vezes se posicionarem em lugares um pouco diferentes, partilham a problematização da constituição da docência, pois, segundo Diaz (1999, p. 15), " [...] consideramos que não existe sujeito pedagógico fora do discurso pedagógico".

Todavia, aponta-se aqui o cuidado em não tratar dessas diferentes perspectivas(tecnicistas, críticas, pós-críticas) de modo hierarquizado ou como 
substituições, evoluções e progressos. Trata-se de tomar o pensamento da diferença como uma possibilidade de problematização do presente. Nesse sentido, este artigo busca atravessar a área da educação e, especificamente o conceito da docência, com o pensamento da diferença para provocar outras possibilidades a partir das dissoluções genealógicas da verdade, da realidade e da identidade apontadas por Foucault. Conforme nos alerta Nietzsche (2006), não há ser por trás do fazer, pois a ação seria tudo. Dessa forma, interessa, aqui, pensar os modos de relação consigo mesmo, no que se refere a esse lugar no discurso que é a docência.

\section{Docências e as dissoluções genealógicas}

Foucault (2002, 2002b, 2003, 201 1), em suas pesquisas arqueológicas, buscou entender as condições de existência dos discursos e como estamos sendo tomados como objetos de conhecimento pelo que chamou de ciências empíricas, pela filosofia moderna e pelas ciências humanas. Como estudioso de Nietzsche, ele iria operar mais adiante com a genealogia, na esteira de seus estudos arqueológicos, como um diagnóstico dos sintomas do presente, perguntando como estamos nos constituindo em relações de poder nas práticas divisoras. E, ainda, em seus últimos estudos pesquisou como estabelecemos determinadas relações conosco mesmos a partir de determinadas práticas de si, sendo esta última perspectiva voltada para uma genealogia da subjetivação.

Nesse sentido,conforme citado acima, muitas pesquisas foram realizadas no sentido de traçar uma genealogia dos discursos da docência, de traçar o funcionamento de tais relações de poder e saber, descrevendo os efeitos de verdade e a produção de modos de subjetivação, ou ainda trazendo essa temática pensada a partir das práticas de si. Todas essas pesquisas e muitas outras instigam nosso pensamento a pensar outras coisas sobre essa problemática.

Opta-se, neste artigo, com base nas produções já realizadas, por tomar a docência no desmanche da verdade, da realidade e da identidade como um procedimento com inspiração genealógica e, ao mesmo tempo, um processo de diferenciação e de irrupção nos modos de existência docentes no presente. A partir da genealogia foucaultiana, que carrega funcionamentos 
arqueológicos, pode-se pensar que, quando tratamos da docência, falamos com base em determinadas regras e categorias, a partir de determinadas condições enunciativas e históricas. Desse modo, aquela não seria um dado natural, um funcionamento generalizado, mas uma produção discursiva, conforme as pesquisas trazidas, no início deste artigo, apontam. Por isso, não pretende-se, aqui, saber o que é mesmo a docência, mas perguntar pelos lugares assumidos quando se exige desse corpo docente trabalho, controle, confissão, salvação, disciplinamento, inclusão, adaptação, ensino e explicação, entre tantos outros.

Foucault traçou diferentes modos de investigação de acordo com suas necessidades de pesquisa, tal como a arqueologia do saber, a genealogia do poder e a genealogia da subjetivação. No conhecido artigo "Nietzsche, a genealogia e a história", Foucault (2003) traça o fazer genealógico como uma contra-história, escapando do funcionamento por origens e essencialismos, apostando no jogo de forças. Trata-se de uma genealogia que busca investigar os sintomas do presente para mostrar um corpo marcado de história, existências sem referentes ou coordenadas originárias, diagnosticando e dizendo a diferença. Desse modo, optou-se por operar com as três dissoluções que Foucault empregou em seu texto - quando do seu estudo da genealogia, para tomá-las como ferramental analítico no desmanche dos modos de existência docentes. Tal exercício, que busca romper com a perspectiva da representação e a submissão ao sujeito cognoscente, poderia ampliar, minimamente, as possibilidades de outras relações consigo.

Dessa forma,uma dissolução a ser encarada pela docência seria a da realidade. A grande parte dos discursos docentes vem produzindo uma relação com a realidade escolar como se ela estivesse dada no mundo exterior, com um sentido em si mesma, esperando para ser coletada e repassada aos alunos. Mesmo os discursos críticos ainda operam com a lógica de que há uma ideologia a ser desmascarada para que o sujeito autônomo possa ter acesso a sua consciência (GARCIA, 2009, 2002, 2002a).

Problematizando tal questão que perpassa a relação da docência com os saberes e com os alunos, pode-se romper com a perspectiva que entende que há um mundo lá fora a ser representado pela linguagem e um sujeito, tal como uma interioridade que o representaria. Isso porque se o saber não está dado na realidade e nem é fruto de uma interioridade humana, pode ser entendido na luta pela imposição de sentidos. Isso exige outra postura docente, além da lei da concordância da qual falava Nietzsche (2009). Por isso, conhecer 
não estaria na ordem da transmissão, da assimilação, do reconhecimento ou da explicação, mas de interpretações infinitas. E interpretação no sentido nietzschiano não como descoberta, mas como invenção (NIETZSCHE, 2006). Esse posicionamento poderia nos levar a um deslocamento do conceito de saber para pensar. Conforme Ribeiro,

[...] o exercício do pensamento não se confundiria com um pensar reflexivo, tal como postula a tradição moderna, mas se encontraria exatamente nessa possibilidade de criação de um pensar singular - outra linguagem, pois. [...] $\bigcirc$ caráter radical da experiência de pensar se encontraria numa dobra estratégica no plano de nossas indagações e de nossos posicionamentos perante a vida: primeiramente a recusa a um modo de questionamento paradoxalmente dócil, que se conserva alheio diante da necessidade de enfrentamento da naturalização do mundo; em seguida, o investimento no ato de problematização das condições linguísticas de produção desse mundo e, sobretudo, de produção de nós mesmos nesse mundo (RIBEIRO, 201 1, p. 620).

Portanto, a perspectiva que opera com a dissolução da realidade parte do entendimento de que as palavras produzem as coisas das quais falam (FOUCAULT, 2002a). Desse modo, o que está em questão não são as condições de validade, mas investigar as condições de possibilidade, uma vez que se rompe com uma lógica de correspondência e coincidência com o real da representação. Escapa-se do mestre da memória, que supriria a ignorância do outro, do qual falava Sêneca, quando se dissolve a realidade como uma entidade metafísica. Assim, abre-se a possibilidade de uma luta contra a moral de rebanho que diminui a vida em nome de valores superiores (NIETZSCHE, 2006).

As metanarrativas educacionais deixam de ser as explicadoras do mundo, passando a entender que são elas que precisam ser explicadas em sua formulação e funcionamento, o que nos abre infinitas possibilidades em se tratando da docência. Opera-se com uma desnaturalização da realidade, o que não significa limpar as relações de poder para se chegar à verdadeira realidade. A questão, então, seria analisar as práticas por meio das quais estamos nos constituindo no que somos para abrir possibilidades de criação de outras composições possíveis. Nietzsche aponta que: 
Somente enquanto criadores! - Eis algo que me exigiu e sempre continua a exigir um grande esforço: compreender que importa muito mais como as coisas se chamam do que aquilo que elas são. A reputação, o nome e a aparência, o peso e a medida habituais de uma coisa, o modo como é vista - quase sempre uma arbitrariedade e um erro em sua origem, jogados sobre as coisas como uma roupagem totalmente estranha à sua natureza e mesmo à sua pele -, mediante a crença que as pessoas neles tiveram, incrementada de geração em geração, gradualmente se enraizaram e encravaram na coisa, por assim dizer, tornando-se o seu próprio corpo: a aparência inicial termina quase sempre por tornar-se essência e atua como essência! Que tolo acharia que basta apontar essa origem e esse nebuloso manto de ilusão para destruir o mundo tido por essencial, a chamada 'realidade'. Somente enquanto criadores podemos destruir! - Mas não esqueçamos também isto: basta criar novo nomes, avaliações e probabilidades para, a longo prazo, criar novas 'coisas' (NIETZSCHE, 2009, p. 96).

Outro movimento traria a dissolução da identidade, quebrando com o entendimento de que teríamos uma essência, uma interioridade, leis gerais do desenvolvimento, uma alma ou um self que nos explicaria. $\bigcirc$ que teríamos seriam efeitos de subjetivação, uma posição no discurso, lugares que ocupamos e vivemos. Por isso, essa subjetivação não diz respeito a uma entidade, mas remete à exterioridade e ao acidente (FOUCAULT, 2002, 2002a, 2003). Foucault opera com o conceito de modos de subjetivação, rompendo com a noção de um sujeito identitário, fixado, essencializado, original, soberano, intencional. $\bigcirc$ que teríamos seriam modos de subjetivação e sua constituição em relações de saber, poder e o si, e não uma forma que é idêntica a si mesma. Apenas relações de forças, rompendo com a lógica platônica-cristã, uma vez que não há um modelo a que pudéssemos nos submeter, uma vez que esse referente não passa de uma invenção.

Trata-se de uma análise das relações de forças, tomando as práticas pelas quais as pessoas são compreendidas e pelas quais se age sobre elas, ou seja, a questão genealógica: como nos tornamos o que somos? Uma investigação dos modos de trabalho dos indivíduos sobre si mesmos que poderia problematizar essa consciência dada em si mesma. Nesse sentido, pode-se problematizar as identidades em relação à docência, tais como: instrutora, avaliadora, salvadora, inclusora, transmissora, conscientizadora, transformadora, 
explicadora e de bom pastor, com todos os efeitos de poder e de subjetivação com os quais estão envolvidas.

A docência dificilmente escapa à moral de rebanho que a divide em boa e má consciência. Nietzsche (2009) já nos alertava sobre as virtudes (e que se pode ler ligadas a tais existências identitárias) e do quanto são prejudiciais e escravizantes para que as "possui". Assim, se poderia experimentar a docência a partir da problematização que Nietzsche (2009) realiza sobre a educação na perspectiva de uma moral de rebanho que encaminha para o bem de todos e para a renúncia de si. Tal docência buscaria produzir utilidades públicas como objetivos superiores a partir de virtudes como obediência, piedade e justiçalessa última conectada com o conceito de vingança a partir da lógica de dano e dor). $\bigcirc$ que abre para perguntas como: justiça para quem? Como se constituiu a valoração desse valor? Obediência a quê?

Daí a necessidade de atenção ao perigo da maioria. Por isso, Nietzsche (2006) nos diz para ficarmos atentos às forças, e sobre o que e como agem, o que produzem, que modos de vida poderiam colocar em funcionamento. Mais do que formação, talvez a grande necessidade seria a de deformação, de esquecimento, de esvaziamento de tantas existências já lota138 das demais em se tratando da docência. Conforme Nietzsche (2009, p. 19), "[...] sadio é quem esquece".

Dessa forma, poderíamos pensar em possibilidades para um viver mais afirmativo, que, conforme Ribeiro (2011, p. 621), "[...] encontra-se na coragem desse embate nos vetores de saber-poder que nos subjetivam". Tratasede uma necessidade, de certa urgência de dissolver o eu, o que exigiria um pensamento sem oposição ou contradição, mas múltiplo (FOUCAULT, 2005a). Isso poderia levar a pensar de que modos estamos sendo convidados, incitados, coagidos e impelidos a nos reconhecermos e a fazermos de nós mesmos um objeto a ser formado, pensado, falado, revelado, fixado quanto à docência e que outras possibilidades microfísicas poderiam ser ensaiadas.

Deste modo, a dissolução da identidade movimenta,também, a relação com o outro e com os saberes, uma vez que o saber não entraria unicamente no jogo de mercadoria, de dar e de receber, nem nos jogos das utilidades, mas tratar-se-ia de transformar-se a si mesmo por meio dessas relações. A dissolução da identidade como um exercício de se estar atento ao que se passa, ao que nos passa, nos transforma, o que se passa no pensamento. 
Tal exercício poderia nos remeter ao conceito de cuidado de si em Foucault (2007, 2007a, 201 1). Para Marcello e Fischer,

A atitude de estar atento àquilo que se pensa seria indissociável daquilo que se faz, que se pratica e que se exerce diante dos outros e diante do mundo. [...] $\bigcirc$ cuidado de si é marcado por um princípio de movimento, que envolve deslocamento e ação; transformação e trabalho (MARCELO; FISCHER, 2014, p. 165).

Ainda outro movimento traz a dissolução da verdade. Nietzsche (2006) problematizou a valoração dos valores, negando o valor "em si" dos mesmos. A verdade passa a ser entendida como uma ficção e um valor que esqueceu que o é. Segundo Foucault (2003a, p. 14), a verdade é "[...] um conjunto de procedimentos regulados para a produção, a lei, a repartição, a circulação e o funcionamento dos enunciados". Assim, entende a verdade como sendo desse mundo, fortemente vinculada a relações de poder que a produzem e a apoiam, constituindo-se, assim, em regimes de verdade. Isso permite problematizar essa moral metafísica que invade os discursos docentes e que se pretende para todos no julgamento das condutas humanas. Tal postura poderia nos levar a perguntar pela condição de invenção dos valores em questão, apostando na multiplicidade ao contrário da busca da unidade pela representação.

A dissolução da verdade passaria, pois, pela problematização da moral de rebanho platônico-cristã que divide o mundo em modelos e cópias, em verdade e erro. Essa moral funciona mediante as forças reativas do ressentimento, da culpa e do ideal ascético, operando por meio da vontade de verdade. Por isso, trata-se do questionamento do valor da verdade. Corazza traz o ressentimento no atravessamento da docência, dizendo que:

Sempre o mesmo chavão: - 'É culpa de...'. Sempre a mesma relação de causalidade: - 'Se tu fosses diferente... Se ele fosse diferente... Se a profissão fosse honrada... Se o meu curso tivesse sido melhor... Se o que me ensinaram na academia fosse útil na prática... Se me pagassem bem... Se o governador... Se o prefeito... Se o sindicato... Se a escola apresentasse condições... Se as famílias fossem estruturadas... Se a comunidade tivesse mais recursos... Se os alunos nos respeitassem... Se os alunos se interessassem... Se os alunos tivessem limites... Se os alunos tomassem Ritalina... Se tudo fosse diferente, então, sim, eu seria uma ótima 
professora! Então, sim, eu seria plenamente realizada! Então, sim, eu seria feliz'! (Sempre a mesma malevolência do ressentimento? perguntaria Nietzsche.) (CORAZZA, 2005, p. 38).

Então, mais do que buscar a verdade sobre a docência, trata-se aqui de pensar o valor de verdade no que tange à docência; de buscar a verdade como mais um valor produzido contingentemente. Isso não significa operar sem nenhum valor, mas mostrar como foram produzidos e qual sua força em nossa contemporaneidade para, quem sabe, inventarmos outras relações conosco mesmos nesse espaço. $\bigcirc$ objetivo não seria distinguir o verdadeiro do falso, o bem do mal, mas investigar como certas questões estão sendo colocadas como regimes de verdade, quais suas regras para distinguir o verdadeiro do falso, analisando-os em seus efeitos específicos de poder e de subjetivação (FOUCAULT, 2003a).

Portanto, é possível problematizar esse mundo racional que pode refutar o erro, se opor à aparência, em busca da essência para pensar de que modo habitamos esses lugares da docência e, para além da questão da verdade ou do erro, se potencializa a vida ou não. E quanto ao viver, Nietzsche (2009, p. 77) dizia que "[...] viver - é continuamente afastar de si algo que quer morrer; viver - é ser cruel e implacável com tudo o que em nós, e não apenas em nós, se torna fraco e velho". Trata-se de pensar a docência no atravessamento das forças microfísicas que a produzem para desempanturrar esse corpo da docência já tão codificado. Um corpo tão cheio de identidades e verdades, para que haja a possibilidade de criação, em brechas, de uma estética da existência.

E como alerta Foucault, isso não significa não ser governado; significa, apenas, não ser governado a esse preço, em nome dessas verdades, em meio a esses procedimentos. Em qualquer instituição de ensino vemos professores atolados de conhecimentos a serem repassados, provas e alunos a serem corrigidas/corrigidos, notas a serem dadas, burocracias a serem encaminhadas, salas de aula que necessitam de certo número de alunos, cuidado com a frequência, pontualidade e vestimentas. $\bigcirc$ lugar da docência não pode ser separado da problematização do disciplinamento dos saberes e dos corpos nos quais ela está envolvida, uma vez que opera em uma instituição de confinamento que sequestra o corpo para produzi-lo de determinadas formas (FOUCAULT, 2002a). 
Isso não significa tentar fazer do lugar da docência completamente outra coisa e nem mesmo negar certa condução, mas esburacá-lo na abertura de pequenos espaços para se pensar em outras possibilidades em frestas microfísicas nessa relação que se assume consigo mesmo. Quais são as coerções a que estão submetidos professores e professoras? Quais efeitos de poder estão produzindo? Como essa política de verdade cientificista vem produzindo modos de existência? Quais técnicas de si estão sendo empregadas para obtenção e confissão da "verdade docente" na contemporaneidade? Segundo Fischer (2001, p. 205), é necessário ouvir os murmúrios da nossa época, "[...] investigar sobre as posições necessárias ao falante, para que ele efetivamente possa ser sujeito daquele enunciado".

Talvez tais problematizações possam deslocar da ordem moral e operar em uma perspectiva mais ética quando pergunta pelos modos de subjetivação, pelos estilos de vida implicados na docência em vez da identidade submetida ao jogo binário e universal. Esse posicionamento exige perguntar pelas práticas que estão produzindo tais relações, deslocando-nos das essências, dos totais para as práticas por meio das quais somos tomados, narrados, explicados e produzidos enquanto docentes.

Desse modo, as três dissoluções genealógicas poderiam funcionar como ferramental analítico para se problematizar a relação entre a docência, a verdade e a constituição da experiência, ou seja, de que modos aprendemos a nos pensar, ver e dizer enquanto docentes. Por isso, além de um conhecer a si mesmo, tratar-se-ia de um ocupar-se consigo. Sêneca dizia que quem ensina se instrui; portanto, o cuidado de si estaria fortemente conectado ao cuidado com o outro, pois seria um princípio do próprio exercício. E é nesse sentido que tais procedimentos rompem com o cuidado de si submetido ao conhecimento de si, para operá-lo como um labor sobre si mesmo, o qual exige a problematização das valorações e pesos que fazemos no presente.

Essa postura poderia nos remeter ao que Veiga-Neto (2012) chamou de ativismo, enquanto compromisso ético consigo mesmo e com os demais. Além de uma militância que opera na lógica da conscientização, essa perspectiva trataria, justamente, da diferença que não se submete ao mesmo. E, obviamente, que mais uma vez não se afirma a defesa de um "isto ou aquilo", mas se chama a atenção para olharmos para as diferentes forças que nos atravessam e nos produzem. 
Foi discutido, portanto, um procedimento genealógico como certa maquinação e desmontagem da lógica identitária na possibilidade de criação de outros sentidos. Não se nega o acúmulo até aqui realizado, não se denuncia o que estaria errado na escola e na atuação de professores, mas se opera além do acúmulo de saberes e informações, apostando no efetivo exercício de pensamento na possibilidade de outras experiências docentes. Conforme Marcello e Fischer, essa formação de si diria respeito,

[...] para além (e na contramão de) um embrutecimento das práticas de transmissão, próprias da vida educacional, constituiu-se basicamente de toda essa entrega a um trabalho minucioso e estético, de si para si mesmo, constante, e que só existe na medida em que está atento ao outro, neste caso, o outro da 'pólis escolar', se assim o quisermos nomear (MARCELO; FISCHER, 2014, p. 169).

\section{Docências e o cuidado de si}

Seguindo essa discussão, seria possível pensar com Foucault (201 1 , 142 2007, 2007a) a docência a partir de seus últimos estudos, os quais foram dedicados à genealogia das práticas de subjetivação, entendendo que este "eu" com o qual se tem uma relação é a própria ação. Daí o estudo das práticas por meio das quais os indivíduos aprendem e estabelecem determinadas relações consigo mesmos, realizando um deslocamento do eu para o si. Com base nesses estudos, Foucault opera com o cuidado de si como essa artesania de produzir uma determinada estética da existência, deslocando de uma moral generalizada, ligada a valores totais. Por isso, a genealogia da subjetivação não opera com um sujeito transcendente, mas busca as práticas e as formas de existência. Isto é, desloca-se da transcendência para o jogo de forças na imanência.

Foucault descreveu (201 1) o cuidado de si em três momentos, não fragmentados, aqui podendo-se pensar muito mais em movimentos. Inicia com o momento denominado de socrático-platônico, sendo o seu aparecimento na história da filosofia com o Alcibíades de Platão (201 1) e com a discussão do cuidado ainda submetido ao conhecimento de si e à preparação de uma vida futura, uma dada posição, ao governo da cidade, e ainda, ligado a uma deficiente pedagogia. O segundo momento foi denominado de helenístico-romano, 
o qual chamou da idade de ouro do cuidado de si, principalmente nos dois primeiros séculos da nossa era.

E, ainda, um terceiro momento que Foucault (201 1) chamou de cartesiano, em que o cuidado de si será denunciado como o que poderia levar a uma conduta individual e egoísta. Esse último momento não começaria com Descartes, mas Foucault marca esse momento cartesiano como o desaparecimento filosófico do conceito, em que há um investimento na filosofia como conhecimento representativo em oposição à filosofia como pensamento e ética de vida. Esse desprestígio vem com a potencialização do cristianismo e com a lógica de se salvar a alma em uma vida que não seria essa, lógica representacional vinda na esteira do platonismo e que invade o funcionamento da ciência, baseada na vontade de verdade. Assim, o sujeito é entendido como uma substância, que poderíamos acessar por meio de alguns métodos de decifração. Desloca-se do processo de criar-se para descobrir-se.

Assim, busca-se, especificamente, alguns conceitos operados por Foucault (201 1), no segundo momento discutido, para problematizar a docência. Para Foucault (20 1 1, 2007a), a partir dessa perspectiva, o cuidado de si remete a um modo de conduzir-se. Trata-se de um fortalecer da diferença para a lidação com o mundo, com os outros e consigo mesmo; de fazer escapes quanto à escravidão dos outros e de si mesmo. Não irá significar autodecrifração de uma substância, mas de inventar estratégias de ampliação e potencialização de determinados modos de existência por meio de diferentes práticas de si. Assim, segundo Gros (2006, p. 130), "Não se trata de provocar em si um desdobramento interior pelo qual eu me constituiria a mim mesmo como objeto de uma observação introspectiva, mas de concentrar-me em mim e de acompanharme".

Dessa forma, retoma-se aqui especialmente a produção do filósofo estoico Sêneca (201 1, 201 1a, 2012, 2012a, 2012b), discutido por Foucault quando da investigação das práticas de si na antiguidade, para pensar a docência atravessada pelo conceito do cuidado de si no presente. Quando Foucault (2011) refere Sêneca para descrever algumas das práticas de si na antiguidade, traz um recorte muito específico que poderia nos auxiliar a pensarmos esse lugar que, hoje,chamamos de docência. Sêneca entendia que, a partir da perspectiva do cuidado de si, exige-se uma relação com o mestre diferente da lógica que operava com base no imperativo do conhecimento de si, uma vez que não se trata de uma relação com o saber que irá 
suprir uma ignorância, uma falta ou uma falha, mas para constituir um corpo. Um processo, portanto, de se criar nas práticas entre o mestre e discípulo,e é exatamente aí que entra o outro.

Rompe-se com a ideia de que estamos falando de um "mestre da memória", que transmite o que o outro ainda não sabe ou que mostra a verdade da realidade dada em si mesma, mas funciona como um dos operadores da relação do indivíduo consigo mesmo. Portanto, trata-se não de explicação, mas de um conduzir-se para fora de si, de uma desaprendizagem (FOUCAULT, 2011 1). Por isso, mais do que uma lidação com o saber como transmissão de um objeto, essa perspectiva fala de uma lidação com o saber no fortalecimento de um corpo e o julgamento da sua utilidade ou não só faz sentido nessa perspectiva.

Daí que o exercício da docência pode ser problematizado nessa função de repasse de repertórios mortos de uma realidade dada em busca de certo reconhecimento de si, para se pensar justamente como uma equipagem para certa existência. A docência tomada pelo cuidado de si exigiria um estar face a face com o outro e consigo mesmo no processo de diferenciação de si. Isso não significa uma relação dialética de negação de si ou de uma lógica que defende "a novidade pela novidade", mas de colocar sua existência como questão de problematização na possibilidade de criação de outros modos de pensamento e de subjetivação. Por isso, esse afastamento de si diria respeito a certa dissolução dos lugares comuns da docência, associados à explicação, à transmissão e à salvação na contemporaneidade.

Rancière traz a ideia da explicação como um modo de funcionamento que fortalece a escravidão, como um embrutecimento, ou seja, aponta que:

A criança que balbucia sob a ameaça de pancadas obedece à férula, eis tudo: ela aplicará sua inteligência em outra coisa. Aquele, contudo, que foi explicado investirá sua inteligência em um trabalho do luto: compreender significa, para ele, compreender que nada compreenderá, a menos que the expliquem. [...] $\bigcirc$ mestre é vigilante e paciente. Ele notará quando a criança já não estiver entendendo, e a recolocará no bom caminho, por meio de uma re-explicação. [...] Mais tarde, ela poderá, por sua vez, converter-se em um explicador. Ela possui os meios. Ela, no entanto, os aperfeiçoará: ela será um homem do progresso (RANCIÈRE, 2004, p. 25-26). 
Dessa forma, retoma-se a ideia de uma necessidade de escape da escravidão que funciona pela ordem da explicação no presente le quem não conhece essa ordem escolar), para outra necessidade: a de uma artesania na docência. Rancière (2004, p. 96-97) diz que: "[...] no ato da palavra, o homem não transmite o seu saber, ele poetiza, traduz e convida os outros a fazerem a mesma coisa". Não diria respeito a um acumular certezas, de um conhecimento que reporte a si mesmo, mas de armar-se no diagnóstico do presente que transforme a si mesmo. Tratar-se-ia de transformar a verdade em ethos e não o sujeito tornar-se um objeto de conhecimento para um discurso verdadeiro (FOUCAULT, 201 1). Assim, o sujeito só existiria enquanto relação consigo, enquanto ação, exercício, sem origem ou fundamento primeiro. Conforme aponta Gros,

[...] seria preciso falar bem mais sistematicamente da 'relação consigo', antes que simplesmente do 'si' em Foucault. $O$ que significa dizer que a subjetividade nele não remete evidentemente nem a uma substância nem a uma determinação transcendental, mas a uma reflexividade que se poderia chamar de prática: uma maneira de se relacionar consigo mesmo para se construir, para se elaborar (GROS, 2006, p. 128).

Com essa opção de pensar a docência a partir do conceito de cuidado de si em Foucault (20 1 1, 2007a), entende-se que poderíamos pensá-la em uma perspectiva mais genealógica. Tomar as dissoluções da realidade, da verdade e da identidade também como um tipo de exercício de si consigo mesmo, no que se refere à docência. E tal procedimento poderia funcionar compondo com a genealogia nietzschiana que problematiza a valoração dos valores e com a genealogia foucaultiana que a traz como uma contra-história no diagnóstico do presente, tal como uma luta contra qualquer essencialismo e que exige certo labor na criação de si mesmo. Tal procedimento genealógico operaria com a docência como uma possibilidade de ação política, aqui, uma micropolítica, atenta aos dispositivos de dominação e à problematização dos regimes de verdade no presente. 


\section{Ainda algumas amarrações: a necessidade do labor e outros pesos}

Foram aqui trabalhadas as possibilidades de se experimentar uma outra relação consigo mesmo no que tange à docência como um modo mais intensivo de conduzir-se. De que valeria uma docência que não se deslocasse e não deslocasse o outro para além de si mesmo? De que valeria uma docência que apenas buscasse semelhanças e produzisse igualdades? De que valeria uma docência que busca um sentido dado em si mesmo para seu exercício? Nietzsche (2009, p. 186) responde a pergunta: "Em que você acredita? Nisto: que o peso de todas as coisas precisam ser novamente determinados".

Tais dissoluções poderiam auxiliar no exame de como a maquinaria subjetivadora e a relação conosco mesmo quanto à docência vem funcionando. Relação essa que, na contemporaneidade, vem tão fortemente perpassada pelos discursos de instrução e de salvação, encerrando a nós mesmos em categorias de: bons, maus, inteligentes, profissionais, repassadores, explicadores, representadores, entre tantas outras que vêm sendo operadas e produzindo certas existências. Daí a necessidade de ficarmos atentos aos discursos que têm funcionado como regimes de verdade e os efeitos de poder e de subjetivação que vêm produzindo. A docência retirada de uma discussão epistemológica de verdade e de erro, assegurada pelas ciências humanas e pela filosofia moderna, poderia ser atravessada pelas dissoluções genealógicas. Isso para tentarmos fazer outras coisas dela: talvez uma bela existência, em brechas.

As práticas do cuidado de sina antiguidade grega e romana foram descritas por Foucault. Retoma-se, aqui, tais práticas como exercício de si para consigo, como um modo de práticas de liberdade, como uma possibilidade ética. Obviamente, aqui não se trata de recuperar esse conceito para ser aplicado na contemporaneidade, mas do quanto isso pode nos afetar a pensar de outros modos a relação de si para consigo, além de uma moral de rebanho, no sentido de criar estratégias de interpelação nos modos de existência no presente. Isso não significa uma nova revolução em educação, uma outra totalidade, uma perspectiva romântica de final feliz, mas de brechas microfísicas nesses modos de existência já tão capturados e codificados por uma lógica da normalização. 
Como alguns estudos já sinalizam, poderíamos alargar as possibilidades do que podemos ver e dizer acerca da docência. Isso porque se tira a discussão de uma tentativa que busca descobrir a essência, a verdade da docência para pensar em estratégias, procedimentos, técnicas em que se tome a si mesmo como objeto de problematização. Tal prática exigiria certo labor, um exercício de si mesmo, no afastamento daquilo que é impeditivo de vida, no sentido nietzschiano.

Desse modo, entende-seque tais procedimentos poderiam passar pelas três dissoluções genealógicas (realidade, identidade e verdade), as quais poderiam funcionar na desnaturalização dos universais docentes, como movimentos de diferenciação. Isso abre possibilidades para a pergunta: de que modos tais dissoluções poderiam operar como procedimento na criação de estratégicas específicas para a invenção de outros modos de existir no que se refere à docência? Procedimentos que poderiam dissolver tais universais em estratégias que perpassem os saberes sobre a docência, os enunciados científicos, as legislações, os instrumentos profissionais, os experts, os rituais, as instituições, as organizações espaço temporais, os sistemas de julgamento e os valores morais.

Talvez, mais importante do que dar respostas, seja, como um outro modo de pensamento, elaborar outras possibilidades de perguntas sobre o tema em questão. Lançar mão de procedimentos para problematizar a linguagem e as categorias por meio das quais estamos nos narrando como docentes, como determinados tipos de docência. Uma docência que entra em relação com pessoas. Uma docência que entra em relação com saberes. Foucault (201 1), a partir do cuidado de si, trouxe a discussão sobre a divisão dos saberes chamados de eruditos (e que poderíamos remeter à lógica enciclopédica dos currículos escolares) e de saberes chamados de etho poiéticos, como aqueles que se atravessam em nosso modo de conduzirmo-nos. Todavia, não se defende um privilegiar de um ou de outro, mas de mostrar a íntima relação entre a docência, a discência e os saberes que estão sendo operados nessa relação.

Não se trataria, então, mais de autodeciframento, de uma autorrevelação ou de uma fixação a si mesmo, mas de certas técnicas de si a serem criadas, além dos sistemas de submissão no jogo das forças. Isso porque entende-seque a experiência que temos de nós mesmos na constituição de um determinado tipo de pessoa é efeito de tecnologias que tomam o humano 
como objeto de produção (ROSE, 1996). Por isso, compõe-se a possibilidade de uma docência mais ativa que trace uma distância entre si e si, pois fala da realização da vida como uma obra a ser produzida. Docências, no plural, múltiplas, infinitas, buscando escapar à escravidão da explicação e da busca de sua identidade.

A docência não passaria mais (ou apenas) como mera transmissora de conteúdos neutros como operada pelo pensamento tecnicista; tampouco como salvadora e conscientizadora conforme é pensada pelas teorias críticas em educação. A docência, dissolvida em frestas, poderia ser remetida a uma obra a ser realizada. Talvez de arte? Que nasça, então, da necessidade; da necessidade de se tornar um mundo, como escreveu Rilke,

Uma obra de arte é boa quando surge de uma necessidade. É no modo como ela se origina que se encontra o seu valor, não há nenhum outro critério. Por isso, prezado senhor, eu não saberia dar nenhum conselho senão este: voltar-se para si mesmo e sondar as profundezas de onde vem a sua vida; nessa fonte o senhor encontrará a resposta para a questão de saber se precisa criar. Aceita-a como ela for, sem interpretá-la. Talvez ela revele que o senhor é chamado a ser um artista (RILKE, 201 1, p. 27).

\section{Referências}

CORAZZA, Sandra Mara. Cenas de uma vida de professora. In: CORAZZA, Sandra Mara. Uma vida de professora. liuí: Unijuí, 2005.

A formação do professor-pesquisador e a criação pedagógica. Revista da Fundarte, Montenegro (RS), v. 11, n. 21, p. 13-16, 2011.

COUTINHO, Karyne Dias; SOMMER, Luis Henrique. Discursos sobre formação de professores e arte de governar. Currículo Sem Fronteiras, v. 11, n. 1, p. 86-103, jan./jun. 2011.

DÍAZ, Mario. Foucault, docentes e discursos pedagógicos. In: SILVA, Tomaz Tadeu da (Org.). Liberdades reguladas: a pedagogia construtivista e outras formas de governo do eu. 2. ed. Petrópolis: Vozes, 1999.

FISCHER, Rosa Maria Bueno. Foucault e a análise do discurso em educação. Cadernos de Pesquisa, São Paulo, n. 114, p. 197-223, nov. 2001. 
FOUCAULT, Michel. Vigiar e punir: nascimento da prisão. Tradução Raquel Ramalhete. 25. ed. Petrópolis: Vozes, 2002.

Arqueologia do saber. Tradução Luiz F. B. Neves. 6. ed. Rio de Janeiro: Forense Universitária, 2002a.

Em defesa da sociedade: curso no Collège de France (1975-1976). Tradução Maria Ermantina Galvão. São Paulo: Martins Fontes, 2002 b.

Nietzsche, a genealogia e a história. In: FOUCAULT, Michel. Microfísica do poder. Tradução Roberto Machado. 10. ed. Rio de Janeiro: Graal, 2003.

Verdade e poder. In: FOUCAULT, Michel. Microfísica do poder. Tradução Roberto Machado. 10. ed. Rio de Janeiro: Graal, 2003a.

A verdade e as formas jurídicas. 3. ed. Tradução Roberto Cabral de Melo Machado e Eduardo Jardim Morais. Rio de Janeiro: Nau, 2005.

Theatrum Philosophicum. In: FOUCAULT, Michel. Arqueologia das ciências e história dos sistemas de pensamento. 2. ed. Organização e seleção dos textos de Manoel Barros da Motta. Tradução Elisa Monteiro. Rio de Janeiro: Forense Universitária, 2005a.

História da sexualidade, 2:0 uso dos prazeres. 12. ed. Tradução Maria Thereza da Costa Albuquerque. Rio de Janeiro: Graal, 2007.

História da sexualidade, 3: o cuidado de si. Tradução Maria T. da Costa Albuquerque. 9. ed. Rio de Janeiro: Graal, 2007a.

A hermenêutica do sujeito: curso dado no Collège de France (1981-1982). Tradução Marcio Alves da Fonseca e Salma TannusMuchail. 3. ed. São Paulo: Martins Fontes, 2011.

FREIRE, Paulo. Pedagogia do oprimido. 17. ed. Rio de Janeiro: Paz e Terra, 1987.

Pedagogia da autonomia: saberes necessários à prática educativa. 12. ed. São Paulo: Paz e Terra, 1999.

GARCIA, Maria Manuela Alves. Pedagogias críticas e subjetivação: uma perspectiva foucaultiana. Petrópolis: Vozes, 2002.

$\bigcirc$ intelectual educacional e o professor crítico: o pastorado das consciências. Currículos Sem Fronteiras, v. 2, n. 2, p. 53-78, jul./dez. 2002a. 
Docência e modos de subjetivação: dissoluções genealógicas e o cuidado de si

. Didática e trabalho ético na formação docente. Cadernos de Pesquisa, São Paulo,v. 39, n. 136, p. 225-242, abr. 2009.

GROS, Frédéric. O cuidado de si em Michel Foucault. In: RAGO, Margareth; VEIGA-NETO, Alfredo (Org.). Figuras de Foucault. Belo Horizonte: Autêntica, 2006.

LOPONTE, Luciana. Da arte docência e inquietações contemporâneas para a pesquisa em educação. Revista Teias, Rio de Janeiro, v. 14, n. 31 , p. 34-45, maio/ago. 2013.

MARCELLO, Fabiana de Amorim; FISCHER, Rosa Maria Bueno. Cuidar de si, dizer a verdade: arte, pensamento e ética do sujeito. Pro-Posições, Campinas, v. 25, n. 2 (74), p. 157-175, maio/ago. 2014.

MATOS, Sônia Regina da Luz. Didática e suas forças vertiginosas. Conjectura, Caxias do Sul, v. 14, n. 1, p. 93-134, jan./maio 2009.

NIETZSCHE, Friedrich. Genealogia da moral: uma polêmica. Tradução Paulo C. de Souza. São Paulo: Companhia das Letras, 2006.

2009.

A Gaia ciência. Tradução Paulo César de Souza. São Paulo: Companhia das Letras,

150 Ó, Jorge Ramos do. A governamentalidade e a história da escola moderna: outras conexões investigativas. Educação \& Realidade, Porto Alegre, v.34, n.2, p.97-1 17, maio/ago. 2009.

PEREIRA, Marcos Villela. Pesquisa em educação e arte: a consolidação de um campo interminável. Revista Iberoamericana de Educacion, Madri, n. 52, p. 61-80, maio/ago. 2010.

PIGNATELLI, Frank. $\bigcirc$ que posso fazer? Foucault e a questão da liberdade e da agência docente. In: SIIVA, Tomaz Tadeu da (Org.). O sujeito da educação: estudos foucaultianos. 4. ed. Petrópolis, Rio de Janeiro; Vozes, 2000.

PLATÃO. Alcibíades. Diálogos VII. Tradução Edson Bini. São Paulo: Edições Profissionais, 2011.

POPKEWITZ, Thomas S. Lutando em defesa da alma: a política de ensino e a construção do professor. Tradução de Magda França Lopes. Porto Algre: Artmed, 2001.

RANCIĖRE, Jacques. O mestre ignorante: cinco lições sobre a emancipação intelectual. 2. ed. Tradução Lílian do Valle. Belo Horizonte: Autêntica, 2004. 
RIBEIRO, Cintya Regina. "Pensamento do fora", conhecimento e pensamento em educação: conversações com Michel Foucault. Educação e Pesquisa, São Paulo, v. 37, n. 3, p. 613628, set./nov. 2011.

RILKE, Rainer Maria. Cartas a um jovem poeta. Tradução Pedro Sussekind. Porto Alegre: L\&PM, 2011.

ROSE, Nikolas. Inventing ourselves: psychology, power and personhood. Cambridge: Cambridge University Press, 1996.

SÊNECA, Lúcio Anneo. Sobre a brevidade da vida. Tradução Lúcia Sá Rebbelo, Ellen Itanajara Neves Vranas e Gabriel Nocchi Macedo. Porto Alegre: L\&PM, 2011.

Aprendendo a viver: cartas a Lucílio. Tradução Lúcia Sá Rebbello e Ellen Itanajara Neves Vranas. Porto Alegre: L\&PM, 2011 la.

Da tranquilidade da alma. Tradução Lúcia Sá Rebbello e Ellen Itanajara Neves Vranas. Porto Alegre: L\&PM, 2012.

Da vida retirada. Tradução Lúcia Sá Rebbello e Ellen ItanajaraNeves Vranas. Porto Alegre: L\&PM, $2012 a$.

Da felicidade. Tradução Lúcia Sá Rebbello e Ellen Itanajara Neves Vranas. Porto Alegre: L\&PM, $2012 b$.

SILVA, Tomaz Tadeu da. Documentos de identidade: uma introdução à teoria docurrículo. 2. ed. Belo Horizonte: Autêntica, 1999.

SOMMER, Luis Henrique. A ordem do discurso escolar. Revista Brasileira de Educação, Rio de Janeiro, v. 12, n. 34, p. 57-67, jan./abr. 2007.

VEIGA-NETO, Alfredo; SARAIVA, Carla. Educar como arte de governar. Currículo Sem Fronteiras, v. 11, n. 1, p. 5-13, jan./jun. 2011.

É preciso ir aos porões. Revista Brasileira de Educação, Rio de Janeiro, v. 17, n. 50, maio/ago. 2012.

Profa. Dra. Betina Schuler Universidade do Vale do Rio dos Sinos | São Leopoldo Escola de Humanidades Programa de Pós-Graduação em Educação 
Pesquisadora do Grupo Interinstitucional de Pesquisa em Docências, Pedagogias e Diferenças | UNISINOS Grupo de Estudo e Pesquisa em Inclusão | UNISINOS Grupo de Pesquisa Cultura, Subjetividade e Políticas de Formação | PUCRS E-mail | betinaschuler@hotmail.com

Recebido 16 jul. 2015 Aceito 22 out. 2015 